Palimpsesto Vol. 11, № 19 (Julio-diciembre, 2021): 31-53

Universidad de Santiago de Chile, ISSN 0718-5898

Simón Timichelle González Monarde

Universidad de Santiago de Chile

simonnomas@gmail.com

\title{
EI universo revisteril de la UTE: redes y debates por la transformación universitaria entre 1947 y 1973
}

\section{The Magazine Universe of the UTE: Networks and Debates for the University Transformation Between 1947 and 1973}

\begin{abstract}
Resumen
Este artículo aborda las revistas político-culturales vinculadas a la Universidad Técnica del Estado de Chile (UTE) entre 1947 y 1973, poniendo atención a los actores que constituyeron propuestas de transformación con las que disputaron los marcos de significación en torno a la relación entre la reforma a la enseñanza técnica y la industrialización nacional. Así identificamos sujetos y grupos que a lo largo de su trayectoria formularon y reformularon proyectos intelectuales, políticos y culturales que circularon mediante las revistas, facilitando el debate a partir de la constitución de redes de sociabilidad relacionadas con la educación técnica y la industria nacional.
\end{abstract}

Palabras claves: Revistas político-culturales, Educación Técnica, Intelectuales, Redes de sociabilidad, Universidad Técnica del Estado de Chile.

\begin{abstract}
This article addresses the political-cultural journals linked to the Technical University of the State of Chile (UTE) between 1947 and 1973, paying attention to the actors who constituted proposals for transformation with which they disputed the meaning frameworks around the relationship between the reform of technical education and national industrialization. Thus, we identify subjects and groups that throughout their trajectory formed and reformulated intellectual, political and cultural projects that circulated through magazines, facilitating the debate based on the constitution of networks of sociability related to technical education and national industry.
\end{abstract}

Keywords: Political-cultural magazines, Technical education, Intellectuals, Social networks, Technical University of the State of Chile. 


\section{Introducción}

En este artículo estudiamos las revistas político-culturales ligadas a la Universidad Técnica del Estado de Chile (UTE) ${ }^{1}$ entre 1947 y 1973. Aquí indagamos en los actores que formularon proyectos intelectuales, políticos y culturales que circularon en distintos espacios y redes de sociabilidad con el propósito de disputar los marcos de significación en torno al sentido de la enseñanza técnica y su relación con la industrialización nacional. En estas publicaciones no sólo se dibujaron formas y ópticas sobre el desarrollo nacional, sino que visiones particulares sobre la política, la cultura y la sociedad que vale la pena recuperar, ya que aportaron un contenido técnico y popular a los proyectos de transformación social del siglo XX.

Los antecedentes de la UTE se vinculan con la historia de la enseñanza técnica, en especial con la Escuela de Artes y Oficios (EAO) creada en 1849 para instruir a la "clase menos acomodada del país" (Muñoz et al, 1987, p. 22), formando obreros con el grado de "Técnico" que si bien gozaron de un prestigio similar al "Ingeniero Civil" de la Universidad de Chile y Católica, no pudieron acceder a este título exclusivo de la elite. Por ende hasta mediados del siglo XX las empresas pagaron salarios inferiores a pesar de cumplir una función ingenieril, produciendo un movimiento de estudiantes y egresados técnicos que consiguió crear la Escuela de Ingenieros Industriales (EII) y el grado de "Ingeniero Industrial" en 1941. No obstante siguieron recibiendo sueldos menores, motivando a la Federación de Estudiantes Mineros e Industriales (FEMICH), ${ }^{2}$ dirigida por el ingeniero eléctrico Enrique Kirberg ${ }^{3}$ (Cifuentes, 1999), a buscar la creación de una universidad industrial que cobijara las escuelas técnicas, ${ }^{4}$ formando la UTE en 1947.

Aunque se abordó la demanda, las escuelas técnicas siguieron funcionando por separado al interior de la universidad, surgiendo problemáticas asociadas a los planes y programas de

${ }^{1}$ Creada el 9 de abril de 1947 en base a la Escuela de Artes y Oficios (EAO) de 1849, Escuela de Minas de Copiapó de 1857 y de La Serena en 1887, la Escuela del Salitre y Minas de Antofagasta en 1918, la Escuela Industrial de Chillán en 1905 (luego traslada al Concepción), Temuco en 1916, Valdivia en 1934, y el Instituto Pedagógico Técnico (IPT) en 1944. En 1957 tuvo una matrícula de 2.427 alumnos, pasando a 8.842 en 1967 y 32.273 en 1973, en su mayoría asociados a los sectores populares. En dictadura fue dividida en diez universidades, una de ellas la Universidad de Santiago (USACH) en 1981. Ver: Muñoz, Juan Guillermo, Carmen Norambuena, Luis Ortega y Roberto Pérez (1988). La Universidad de Santiago. Santiago: Universidad de Santiago de Chile; Rivera, Francisco (2018). Universidad y cambio social: la experiencia histórica de la Universidad Técnica del Estado Chile 19471981. Santiago: Tesis para optar al grado de Magister en Historia con Mención en América Latina, USACH.

${ }^{2}$ Fundada en 1945 por 50 delegados en el Teatro de Artes de la Escuela de Artes y Oficios. Fue presidida por Enrique Kirberg, generando alianzas con partidos, movimientos, intelectuales, congresistas, empresarios, ministros y otros. En su fundación hubo estudiantes de todo Chile, como su Secretario General Julio del Río de la EAO, los Vicepresidente Demetrio Aymans de Copiapó, Gilberto Espinoza de La Serena, Ernesto Días de Castro, Nemesio Sepúlveda de Concepción, Orfilio Garrido de Valdivia, y otras Secretarias a cargo de Ramón Escobar, Jorge Garrido, Mario Carrasco y Luis Rueda, demostrando que la unidad del movimiento fue a nivel nacional.

${ }^{3}$ Nacido en Santiago en 1915. Estudio electricidad en la EAO, participó del "Soviet" de la Universidad de Chile durante la Republica Socialista de 1932, luego milita en el PC y expulsado de la EAO en 1934, reintegrándose en 1941, continuando estudios de Ingeniería en la EII. Luego de trabajar en ingeniería y docencia, fue electo Rector de la UTE entre 1968 y 1973. En dictadura estuvo detenido en Dawson, vive su exilio en Canadá y México. Fallece en Santiago en 1992. Para revisar su participación en este y otros acontecimientos ver: González, Simón (2021). La Trayectoria de Enrique Kirberg y el proyecto educativo popular de la Reforma Universitaria en la Universidad Técnica del Estado de Chile (1930-1973). Santiago: Revista Revueltas, N³, pp. 3-33.

${ }^{4}$ Estas son la Escuela de Minas de Copiapó fundada en 1857 y de La Serena en 1887, la Escuela del Salitre y Minas de Antofagasta en 1918, la Escuela Industrial de Chillán en 1905 (luego traslada al Concepción), de Temuco en 1916, de Valdivia en 1934, y el Instituto Pedagógico Técnico (IPT) en 1944. Sus estudiantes podían continuar sus estudios desde cualquier escuela minera o industrial en carreras de la EAO, la EII y luego el IPT. 
estudio, la expansión de la matrícula y la democratización universitaria. Esto motivó la huelga de la Federación de Estudiantes de la Universidad Técnica (FEUT) ${ }^{5}$ del 25 de mayo de 1961, la que se extendió a todas las sedes. Allí se buscó una "doble democratización" - interna en la toma de decisiones y externa en la expansión del acceso (Ireland \& Rivera, 2016, p. 30)- que fue conseguida tras el Claustro Pleno de agosto de 1968 donde se elige como rector a Kirberg y que inaugura la reforma universitaria, coincidiendo con otros movimientos universitarios ${ }^{6}$ acentuados con la crisis económica y el giro conservador del gobierno de Eduardo Frei a partir de 1967. Así, en paralelo a las experiencias del movimiento obrero y los sectores populares, los técnicos construyeron expectativas que tuvieron respuesta durante la reforma, coincidiendo con el protagonismo popular y rebelión juvenil en sucesos como la Revolución Cubana, la guerra de Vietnam o el movimiento por los derechos civiles en Estados Unidos.

Tras la reelección de Kirberg en agosto de 1969 se crean espacios como la Secretaría Nacional de Extensión y Comunicación (Ireland et al, 2016), materializando el vínculo Universidad-Sociedad al potenciar las expresiones culturales estudiantiles mediante la extensión universitaria. En ese sentido uno de los elementos claves de la reforma en la UTE fue una política de ingreso regular para los grupos populares y la fuerza trabajadora, ${ }^{7}$ estableciendo convenios con organizaciones sindicales para formulas específicas de estudio que produjeron mayor presencia de esos sectores frente a otras instituciones (Garretón \& Martínez, 1985, p. 29). Y a diferencia de espacios universitarios estatales y privados en que se formaron las tradicionales elites intelectuales de matriz laica o católica (Brunner \& Catalán, 1985, p. 265), la UTE se caracterizó por el vínculo de sus actores con el mundo popular, los trabajadores y la cultura de las izquierdas.

¿En qué revistas político-culturales vinculadas a la UTE circularon las expresiones culturales, los proyectos de transformación y los debates intelectuales que disputaron el sentido de la enseñanza técnica y la industrialización nacional? Respondemos lo anterior a partir de la materialidad de las revistas como fuentes privilegiadas para conocer la historia de la circulación de las ideas y como artefactos culturales que facilitan el desarrollo del pensamiento reflexivo (Isava, 2009). Así planteamos que los actores de la UTE disputaron los marcos de significación

${ }^{5}$ Creada alrededor de 1952 o 1953 con la intención de resolver las problemáticas estudiantiles. En los sesenta fue dirigida por Daslav Ursic en 1961; Juan Vera en 1962 que luego fue reemplazado por Omar Martínez; Guido Castilla (DC) en 1963 y 1964; Vladimir Álvarez (DC) en 1965; Alejandro Yáñez en 1966, 1967, 1969 y 1970; Raúl Palacios en 1968; Alejandro Yáñez en 1969 hasta Junio de 1970 cuando renunció y lo asumió Víctor Díaz; Alberto Ríos en 1971 y 1972; y Osiel Núñez en 1973.

${ }^{6}$ Allí fue elegido Fernando Castillo en la U. Católica en octubre de1968; Edgardo Enríquez en la U. de Concepción en diciembre de 1968 y Carlos Von Plessing en 1972; Raúl Allard Neummann en la U. Católica de Valparaíso; William Thayer en la U. Austral; Jaime Chiang en 1968 y Domingo Santa María en 1972 en la U. Técnica Federico Santa María; Miguel Campo en la U. del Norte en 1969; y Edgardo Boeninger en la U. de Chile en enero de 1969

${ }^{7}$ Sobre la Reforma Universitaria en la UTE ver: Kirberg, Enrique (1981). Los nuevos profesionales. Educación Universitaria para trabajadores 1968-1973. México: Universidad de Guadalajara; Cifuentes, Luis (1994) (ed.). La Reforma Universitaria en Chile 1967-1973. Santiago: Fundación E. Kirberg; Rivera, Francisco (2018). Universidad y cambio social: la experiencia histórica de la Universidad Técnica del Estado Chile 1947-81. Santiago: Tesis para optar al grado de Magister en Historia con Mención en América Latina, USACH; Ireland, T. \& Rivera, F. (2016). LA UTE VIVE: Memorias y testimonios de la reforma universitaria en la Universidad Técnica del Estado. Chile 1961/1973. Santiago: Corporación Cultural USACH; González, Ana (2017). Reforma y Revolución en la Universidad Técnica del Estado: las Juventudes Comunistas de Chile y el movimiento estudiantil 1967-1973. Santiago: Tesis de Magister en Historia, USACH; Torres, Rita (2017). Revolución de los papeles. Una mirada desde la Revista de la Universidad Técnica del Estado (1969-1973) para la construcción de memoria del Taller Gráfico UTE. Santiago: Tesis para optar al grado de Diseñadora Gráfica de la Universidad de Chile; entre otros. 
en torno al sentido de la educación técnica y la industrialización nacional, constituyendo espacios como las revistas político-culturales donde circularon proyectos intelectuales enriquecidos por diferentes generaciones de estudiantes, egresados y profesores técnicos. De esta forma relevamos el sentido de la educación técnica en un contexto marcado por reformas estructurales y proyectos populares fracturados por la dictadura, y en un vínculo con el presente donde se plantea redefinir el marco institucional del proyecto de desarrollo nacional, se busca reponer estas experiencias como un incentivo a la reflexión a partir de un pasado relativamente reciente.

Nuestra investigación se enfoca por un lado desde la perspectiva de la historia intelectual, que a partir del giro hermenéutico da relevancia al proceso de comprensión e interpretación de los sujetos y a la confrontación política de los intelectuales con diferentes concepciones de mundo (Queipo, 2004). Por otro lado, la historia política viabiliza "re-percibir" lo político como "algo fundamental en la vida cotidiana de los sujetos" colocando la tensión "en los actores y los procesos creadores de poder" (Moyano, 2011, p. 228). De esta forma, buscamos restituir los contextos de aparición de revistas, los cambios en los proyectos intelectuales y la acción política, los momentos de circulación, recepción y apropiación de ideas, y la producción material de los actores involucrados en la creación de las publicaciones.

En esa línea miramos las revistas político-culturales como soportes materiales para la circulación de ideas políticas y culturales (Zamorano, 2018, p. 12), constituyendo redes de sociabilidad como "principio de las relaciones entre las personas" (Agulhon, 1986, p. 10), donde el hecho de compartir un espacio otorga o potencia una identidad (Rebolledo, 1995, p. 89). El campo revisteril en nuestro continente se inscribe en el "ciclo de las revistas culturales latinoamericanas" desarrollado desde 1890, donde "el escritor, el ensayista, el científico, el intelectual se van diferenciando del político polivalente del siglo XIX" (Tarcus, 2020, p. 20). Esto da paso a una producción revisteril que cruza todos los órdenes de la cultura y que permite seguir los avatares de la vida intelectual de distintos grupos, complejizando los estudios de historia intelectual con un giro material relacionado al texto y su edición, facilitando un acercamiento a la historia cultural y la historia política de los intelectuales.

Sus miembros son voluntarios que se desenvuelven en un espacio privado donde ocurre el debate, se diseña y toman decisiones, y en un espacio público donde influyen en la realidad para transformarla (Pluet-Despatin, 1992, p. 9), configurando "un campo de fuerzas donde los distintos colectivos luchan por la hegemonía cultural y reconfiguran incesantemente sus identidades" (Tarcus, 2007, p. 3). Allí encontramos sujetos que si bien no se reconocen como intelectuales, cumplen ese rol en los "espacios científicos, humanistas o artísticos [que] dialogan con la realidad política y social" (Lozoya, 2013; p.182.), interpretando el contexto y dando un orden simbólico a los fenómenos sociales al pensar transformaciones antes de su implementación. Además, son reconocidos por sus pares a partir de un modo de sociabilidad particular que ofrece un lugar para desarrollar el trabajo intelectual y dar continuidad a la expresión del pensamiento político, produciendo códigos comunes de comprensión de la realidad.

El enfoque metodológico corresponde a un análisis inductivo y explicativo, procesando la información con revistas, libros y testimonios de la época en estudio, cuyas fuentes se encuentran en la Biblioteca Nacional, el Archivo Patrimonial de la USACH y en plataformas digitales. Así analizamos las revistas a partir de su dimensión material e inmaterial considerando sus aspectos de contenido de los artículos, propaganda o secciones, y su geografía humana identificando escritores, directores, editores, diseñadores, intelectuales y otros sujetos (Pita el al, 2015), complementando esta información con testimonios y bibliografía que develan las dinámicas de sociabilidad que no son visibles por la fragmentación de las revistas. En esa línea, ponemos 
atención a los debates y a los itinerarios de sujetos, hitos claves, actores con quienes se vincula, $\mathrm{y}$ el reconocimiento de líderes o pares de confianza en otras colectividades con quienes dialoga (Moyano, 2013, pp. 89-92), determinando las conexiones a partir de las trayectorias que activan en distintos lugares y muestran instantes de agotamiento o continuidad de una revista y/o de un agrupamiento humano.

El universo revisteril en torno a la UTE se compone por publicaciones de distintos agrupamientos de estudiantes, egresados, funcionarios y académicos, cuyo acervo dividimos en tres partes en este artículo. La primera aborda desde la aprobación del Estatuto Orgánico en 1947 hasta la creación del Colegio de Técnicos en 1958, protagonizada por asociaciones de estudiantes y egresados técnicos que disputaron el marco legal del proyecto universitario. La segunda abarca desde 1959 hasta 1967, donde toman protagonismo las revistas editadas por profesores y grupos políticos estudiantiles que formularon proyectos trasformación y desarrollaron estrategias de acción en esa línea. La última parte aborda el periodo de la reforma universitaria entre 1968 y 1973, donde se implementaron transformaciones que buscaron extender el ingreso universitario y acercar esta institución cultural a amplios sectores sociales.

\section{Revistas en la conformación institucional de la UTE: 1947-1958}

En esta primera etapa, existen boletines y revistas creadas por estudiantes y en su mayoría por los egresados de la enseñanza técnica. Poco antes de la creación de la UTE encontramos una de las primeras publicaciones de esta etapa, donde circuló el boletín de la FEMICH titulado "Anteproyecto de Universidad Industrial del Estado: estudio realizado en el 1er Congreso Nacional de Estudiantes Industriales y Mineros" publicado el 20 de septiembre 1945. En su congreso fundacional esta federación fue presidida por Enrique Kirberg, de dónde provino "la idea de crear una Universidad Industrial que cobijara a todas las escuelas chilenas que daban cursos de nivel terciario" (Cifuentes, 1999, p. 23), creándose la "Campaña Pro-Universidad Industrial del Estado".8

Las publicaciones de la Organización de Técnicos de Chile (OTECH) fundada el 18 de noviembre de 1947, tuvieron una estrecha relación con las redes de egresados, organizaciones, propuestas y debates en torno a la educación técnica desde inicios del siglo XX, ${ }^{9}$ agrupando a más de seis mil socios de distintas escuelas. Tras su primera convención nacional formaron un Directorio Ejecutivo Nacional (DEN) ${ }^{10}$ encabezados por los técnicos Luis Faure Araya ${ }^{11}$ como

${ }^{8}$ En tal proceso participaron la Radio de la SONAMI presidida por Hernán Videla Lira, el Partido Comunista, Socialista, Radical, autoridades como ministros, senadores, diputados, además de diarios y organizaciones sindicales como la FOCH, la FECH, y autoridades de las escuelas técnicas regionales.

${ }^{9}$ Una de las primeras organizaciones de egresados fue el Centro de Ex Alumnos de la EAO creada por más de cuarenta egresados en 1912, ellos Santiago Bozzo, Jorge Tiska, Manuel Araya Valverde y Francisco Melivilu. En marzo de 1928 esta se transforma en la Sociedad de Fomento Industrial "Escuela de Artes" presidida por el técnico O'Higgins Palma y desde 1936 se refunda como la Asociación de Técnicos Industriales de Chile y el Instituto de Técnicos de Chile donde participaron los antes mencionados junto a Alfredo Serey, Raúl Ramírez Monreal, Luis Faure y José Miguel Seguel, Rector de la UTE entre 1953 y 1957. Finalmente, a partir de la Asociación y el Instituto, fue creada la OTECH el 18 de noviembre de 1947 presidida por Faure y Seguel, siendo la base del Colegio de Tëcnicos de Chile creado por ley durante 1958

${ }^{10}$ Allí participan como Segundo Vicepresidente Camilo Saavedra, Secretario General Víctor Villalobos, Tesorero Feliz Ortiz, Secretario de Prensa y Propaganda Roberto Wieland, Secretario de Actas Omar González, Secretario de Correspondencia Alfredo Serey Vial, los Directores Adrián Rubio, Domingo Rojas, Carlos Arriagada, Alejandro 
presidente y José Miguel Seguel ${ }^{12}$ como vicepresidente. Asimismo se creó una publicación informativa que tuvo tres épocas: el Boletín informativo OTECH de 1949; la Revista OTECH publicada entre 1952 y 1957; y la Revista Técnica OTECH publicada entre 1958 y 1960.

\begin{tabular}{|c|c|c|c|}
\hline Ã̃OS & ORIGEN & REVISTAS & DEBATES \\
\hline $\begin{array}{l}1945 \\
1947\end{array}$ & Estudiantil & Boletín FEMICH & $\begin{array}{l}\text { Propuesta y creación de la UTE. } \\
\text { Planes y programas de estudio. }\end{array}$ \\
\hline $\begin{array}{l}1948 \\
1960\end{array}$ & Egresados & $\begin{array}{l}\text { Boletín OTECH } \\
\text { Revista OTECH }\end{array}$ & $\begin{array}{l}\text { Estatuto Orgánico de la UTE. } \\
\text { Colegio de Técnicos y Colegio de } \\
\text { Ingenieros. } \\
\text { Ciencia y tecnología. }\end{array}$ \\
\hline $\begin{array}{l}1958 \\
1966\end{array}$ & Institucional & $\begin{array}{l}\text { Festividades } \\
\text { Aniversarias } \\
\text { ERG Concepción } \\
\text { Gaceta Universitaria }\end{array}$ & $\begin{array}{l}\text { Cultura universitaria (Circo, Teatro, Coro, } \\
\text { Folklore, Cine) } \\
\text { Planes y programas de estudio. } \\
\text { Ciencia y tecnología. }\end{array}$ \\
\hline $\begin{array}{l}1960 \\
1973\end{array}$ & Estudiantil & $\begin{array}{l}\text { Vértice } \\
\text { Brecha } \\
\text { El Decito } \\
\text { El Universitario }\end{array}$ & $\begin{array}{l}\text { Movimiento estudiantil. } \\
\text { Reforma Universitaria. } \\
\text { Planes y programas de estudio. } \\
\text { Cultura y deportes universitarios. }\end{array}$ \\
\hline $\begin{array}{l}1967 \\
1973\end{array}$ & Institucional & $\begin{array}{l}\text { Cuadernos de la } \\
\text { Reforma } \\
\text { Revista de la UTE } \\
\text { Talleres de la } \\
\text { Cultura } \\
\text { Contribuciones } \\
\text { Presencia UTE } \\
\text { Unitécnica }\end{array}$ & $\begin{array}{l}\text { Avances de la Reforma Universitaria. } \\
\text { Noticias sobre la UTE } \\
\text { Ciencia y tecnología. } \\
\text { Debates intelectuales y políticos de la UP. } \\
\text { Hitos internacionales a favor y contra la UP. }\end{array}$ \\
\hline
\end{tabular}

Las revistas respondieron al "común anhelo de todos los técnicos del país que desean disponer de una fuente de información de los problemas que agitan a nuestra Organización" (Boletín Informativo, diciembre 1949, Nº3, p. 3). Sus contenidos abordaron cuestiones políticas y culturales, la colaboración internacional, discursos de dirigentes, efemérides de socios y asociaciones, o las resoluciones de la FEMICH (p. 13). También informaron sobre las leyes de

Torres Correa, Eduardo Frenk, los Directores Suplentes Luis Zanoni y Francisco Fuentealba, y el Tribunal de Disciplina con Norberto Toledo, Luis Oportus, Wencenlao Sepúlveda, Juan Hernández y Ovidio Sagués.

${ }^{11}$ Sobre Luis Faure Araya no se ha logrado obtener mayor información.

${ }^{12}$ Electro técnico de la EAO y abogado de la U. de Chile, realizando su memoria "La Industria Eléctrica ante la Legislación Chilena". Fue profesor de la EAO, Presidente de la Asociación de Técnicos Industriales y confeccionó los Estatutos de la Organización. Participó de la Comisión Redactora del Estatuto Orgánico y fue Rector de la UTE entre 1953 y 1957. 
Estatuto Orgánico de la UTE y colegios profesionales aprobadas durante 1952 y 1958 respectivamente, y en torno al Hogar Social del Técnico, una sociedad inmobiliaria de propiedad de los socios que serviría para autofinanciar la organización. En ese sentido, generaron una identidad y una cultura política compuesta por diferentes círculos de egresados técnicos que replicaron estos aprendizajes en las publicaciones de sus asociaciones.

Allí se articularon egresados y estudiantes en torno a sus demandas, propuestas y acciones colectivas, dando cuenta de la constitución de actores y redes de sociabilidad desarrolladas desde la primera mitad del siglo XX. Algunos pertenecieron a distintas generaciones de técnicos, identificando a ex alumnos de la EAO como Alfredo Serey, Alejandro Torres, Gustavo Erazo, José Miguel Seguel y Enrique Kirberg, o profesores como Enrique Froemel, Armando Quezada, Manuel Rodríguez Valenzuela, Octavio Lazo o Rubén Toro, quienes fueron un puente entre sus organizaciones y las luchas de los técnicos de los años veinte y treinta ${ }^{13}$. En ese sentido, conformaron redes de técnicos que buscaron incidir en la conformación institucional, la regulación profesional y los programas de estudio de la UTE. No obstante, vemos como la mayoría de estos sujetos fueron hombres, lo que fue cambiando en la medida que comenzaron a ingresar estudiantes y profesoras mujeres durante el siglo XX.
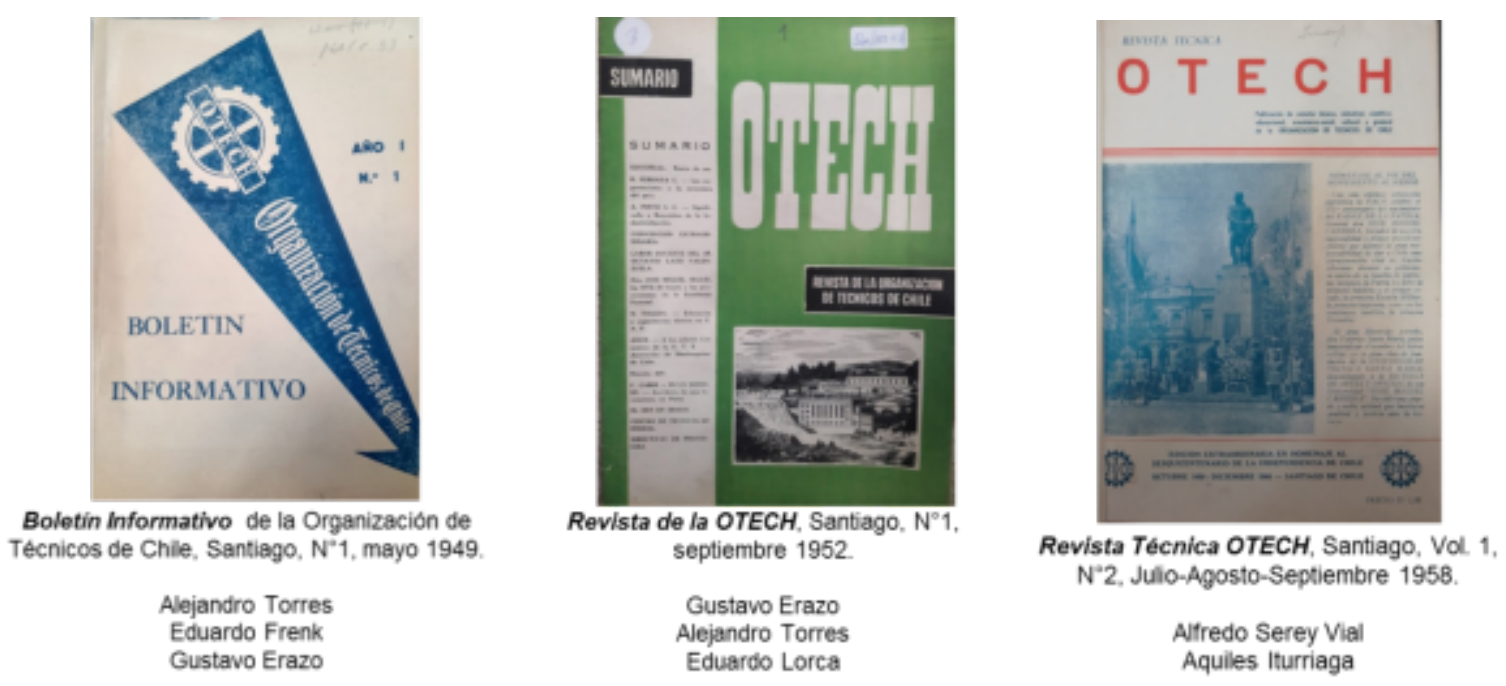

Respecto a los estudiantes, es interesante como a través de la creación de espacios culturales y deportivos argumentan la reforma de los programas y planes de estudios por la escaza complementariedad de las carreras, planteando la necesidad de una educación integral con

${ }^{13}$ Influenciados por la Reforma Universitaria Argentina de 1918, los alumnos técnicos participaron en las huelgas de los años veinte (Cruces, 2012, p.13) y más tarde crearon la Asociación de Estudiantes Industriales el 30 de julio de 1931 en el teatro de la EAO (Serey, 1931, p. 89) con el objetivo de lograr la reforma de la enseñanza técnicoindustrial mediante una institución para especializarse en Ingeniería. Así encabezaron las movilizaciones de agosto donde participaron estudiantes de las escuelas industriales de Temuco, Concepción y Copiapó, y de egresados que laboraban en diferentes lugares del país. Allí se creó el Comité de Padres, Apoderados y Ex Alumnos y el Comité de Profesores, cuyos integrantes facilitaron la resolución del conflicto, destacando la agencia de egresados como Jorge Tiska y O'Higgins Palma de la Sociedad de Fomento Industrial; el cirujano dentista Mauricio Baltiansky, tío de Enrique Kirberg; profesores de la EAO como Enrique Froemel; el dirigente de la Asociación de Estudiantes Industriales Alejandro Torres Correa; y el influyente egresado Alfredo Serey que publicó numerosos artículos de prensa debatiendo con el Director General de Enseñanza Industrial don Ramón Montero y el Gobierno . 
cursos humanísticos, deportivos y culturales, infraestructura adecuada y mejorar el acceso de los sectores populares. De hecho tras la primera candidatura de Enrique Kirberg en 1959, algunos estudiantes y profesores diseñaron propuestas para transformar la universidad, cambiando la forma de hacer política y los medios para lograrla. Así en la tradicional disputa por la rectoría entre los sectores conservadores y la masonería, aparece un nuevo sector con una matriz política de izquierda a la que adhieren grupos de egresados, estudiantes y más tarde profesores.

\section{Revistas y propuestas para la reforma universitaria: 1959-1967}

Durante el segundo periodo tomaron protagonismo las revistas institucionales y estudiantiles, las que dieron relevancia a la cultura universitaria y las problemáticas del movimiento estudiantil. Entre las publicaciones institucionales encontramos la revista Festividades Aniversarias entre 1958-1959 y ERG de 1961 editadas por profesores de la Escuela de Técnicos Industriales de Concepción de la UTE. En Santiago destacó la revista Gaceta Universitaria entre 1965 y 1966, mostrando los cambios en la universidad, el desarrollo cultural y científico. Sus páginas expresaron la búsqueda por colaborar en el desarrollo cultural y político, informando sobre aniversarios de escuela, concursos literarios, congresos de la FEUT y cuestiones en torno a la productividad industrial, la pedagogía, la infancia, la vulnerabilidad de la niñez y sus efectos en el desarrollo de la delincuencia juvenil.

Tanto Festividades ${ }^{14}$ como $E R G^{15}$ tuvieron entre veinte y treinta páginas, siendo editadas por profesores junto a la participación de estudiantes que abordaron los grupos culturales, concursos literarios y temas valóricos sobre el trabajo y la educación. En el caso de ERG se expresó su trayectoria histórica en su diversa composición expresó, ya que esta fue la segunda época de la revista del mismo nombre publicada en la Escuela de Técnicos Industriales de Concepción entre 1945 y 1952. Esto explicaría la distribución de roles en ambas revistas, donde Festividades tuvo tres integrantes, mientras que ERG llego a tener a más de diez. En cuanto a Gaceta Universitaria, aunque no fue posible determinar sus integrantes, en ella se manifiesta un interes respecto a los grupos culturales estudiantiles, alianzas con empresas o instituciones, e informaciones en torno a leyes que facilitan la reforma universitaria.

En su búsqueda por ser reconocidos como verdaderos universitarios, los estudiantes desarrollaron actividades culturales en la mayoría de las sedes, destacando desde 1948 el Circo Minero de Copiapó. Asimismo la Radio estudiantil Atacama o la Radio Escuela Experimental constituidas en 1943 y 1956 respectivamente, si bien muestran un cambio en las formas de circulación de las ideas, evidencian el estrecho vínculo entre las expresiones culturales desarrolladas en la UTE, donde luego de diez años de funcionamiento surgieron nuevos espacios y redes sociales que contribuyeron en la conformación de su identidad. De hecho, no fue casual que surgieran grupos teatrales impulsados por profesores y estudiantes como TUEMCO ${ }^{16}$

${ }^{14}$ Allí participaron los profesores Lucas Machuca F. como su Director, Alicia Ascencio Rocha como Asesora de Redacción y Patricio González como diseñador de la portada.

${ }^{15}$ En su directorio estaban Jorge Svoboda, el Secretario de Redacción Luis Saavedra, el Tesorero Miguel Carrasco y los colaboradores Nelson Semmler, Flor Martínez y Liser Viverc junto a los alumnos Julio Jofré, Ramón Turra, Julio Álvarez, Carlos Villagrán y Lüdwig Wünkhauss.

${ }^{16}$ Teatro Universitario Teatro Universitario de la Escuela de Minas de Copiapó, cuya primera presentación fue la velada del 14 de octubre de 1959 con la obra "Otra vez el diablo" del dramaturgo español Alejandro Casona, y al igual que la Radio Atacama quedó a cargo del Centro de Extensión Cultural estudiantil. 
dirigido por Raúl Naveas en Copiapó, el TEUT ${ }^{17}$ por Graciela Batarce en Concepción en 1957 y el Teatro Teknos ${ }^{18}$ por Alfredo Mariño en Santiago en 1958, cuyas obras circularon en la Radio UTE y en el Festival Nacional de Teatro. En esa línea dichas publicaciones permiten reponer actores que constituyeron redes de sociabilidad y un movimiento cultural que contribuyó en la formación de una identidad técnica y popular en la UTE, en especial los coros universitarios. ${ }^{19}$
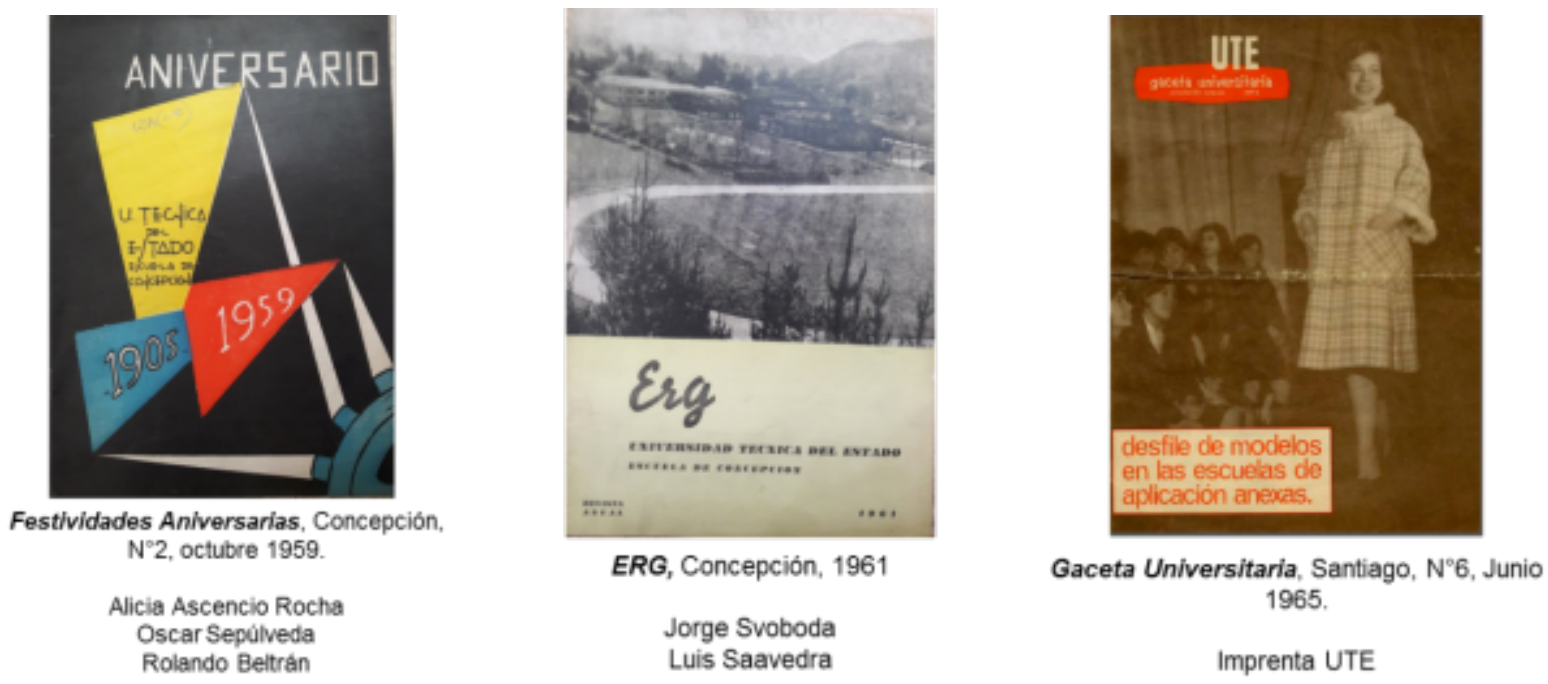

Dentro del segundo grupo encontramos publicaciones estudiantiles como Vértice del centro de alumnos ${ }^{20}$ de la Escuela de Ingenieros Industriales publicada entre 1959 y al menos hasta 1971; el periódico Brecha publicado entre 1962 y 1973 por algunas de las juventudes políticas que encabezaron la Federación de Estudiantes de la Universidad Técnica (FEUT); ${ }^{21}$ y la

${ }^{17}$ Teatro Experimental Universidad Técnica, que luego del retiro de Batarce en 1959, su organización fue asumida por la Secretaria de Cultura del Centro de Alumnos de la Escuela de Técnicos Industriales de Concepción.

${ }^{18}$ Para un estudio detallado ver: Archivo Patrimonial USACH (2019). Teknos. El teatro de la UTE 1958-1977. Santiago: Editorial Usach.

${ }^{19}$ En los cincuenta se desarrolló una potente red de conjuntos corales donde el director Mario Baeza y Rene Rosales fueron articuladores de diferentes grupos y espacios, constituyendo el Coro Mixto dirigido por el estudiante Mario Puentes Montealegre desde 1951, René Rosales desde 1955 y Mario Baeza cuando se convierte en el Coro Polifónico de la UTE en noviembre de 1956, y el Coro de la ETIC impulsado por el estudiante Eduardo Paredes y el profesor Sergio Beltrán en 1957 en Concepción. Aquí la figura de Baeza es clave en el impulso que del movimiento coral chileno como fundador y presidente de la Federación de Coros de Chile en 1956 y su revista Voces, donde se evidencia una red de directores compuesta por Rosales, Waldo Aránguiz, Gustavo Morales, René Álvarez, Hugo Colima, entre otros, y de la Federación Internacional de Coros de América de Antofagasta en 1963 y de Viña del Mar al año siguiente, donde asistieron 65 y 164 coros del continente respectivamente.

${ }^{20}$ Cuando su Ejecutivo fue elegido en septiembre de 1958, fue integrado por el Presidente Domingo Chávez, Secretario General Hugo Quintana, Delegado a la Asociación de Ingenieros Industriales Mario Páez, Delegado al Consejo Universitario Tomás Fürst, Secretario de Actas Domingo Osorio, Secretario de Bienestar Sergio Beltrán, Secretario de Cultura Carlos Viovy, Secretario de Finanzas Jorge López, y Secretario de Prensa Ciro Oyarzún.

${ }^{21}$ Dirigida por Daslav Ursic en 1961; Juan Vera en 1962, reemplazado por Omar Martínez; Guido Castilla (DC) en 1963 y 1964; Vladimir Álvarez (DC) en 1965; Alejandro Yáñez en 1966, 1967, 1969 y 1970; Raúl Palacios en 1968; Alejandro Yáñez en 1969 hasta Junio de 1970 cuando renunció y lo asumió Víctor Díaz; Alberto Ríos en 1971 y 1972; y Osiel Núñez en 1973. 
Revista Literaria publicada por estudiantes del Instituto Pedagógico Técnico (IPT) a partir de 1962 hasta por lo menos 1966. Los contenidos de las revistas se relacionaron con las actividades desarrolladas por los estudiantes de la FEUT y sus propuestas de reforma universitaria, planteando la incorporación de cursos deportivos, cultuales y de ciencias sociales para incentivar la salud física y la reflexión crítica de la sociedad.

Con alrededor de cuarenta páginas, Vértice apareció en junio ${ }^{22}$ de 1959 y reaparece tras las movilizaciones de mayo de 1961. Allí participaron jóvenes dirigentes comunistas como Daslav Ursic, ${ }^{23}$ Ciro Oyarzún, Carlos Viovy, Leonardo Fonseca, Juan Vera Gandulfo, ${ }^{24}$ Tomás Ireland, Víctor Otero, Alejandro Yáñez y Raúl Palacios, y más tarde Horacio Correa, Hugo Jorquera, Guido Herrera, Juan Gandulfo ${ }^{25}$ y Cristián Poulsen. ${ }^{26} \mathrm{Al}$ igual que el primer número, los artículos de Vértice informaban sobre el Centro de Alumnos, la FEUT, la actividad cultural (teatral, literaria y coral) y deportiva, la educación técnica, conocimientos y avances científicos. En 1963 se creó el Suplemento de Vértice editado en cuatro planas de papel periódico, concentrando información sobre el centro de alumnos, sus secretarías, las problemáticas estudiantiles y poemas, editándose. Mientras que Vértice llego tener más de cuarenta páginas con análisis de expresiones culturales y obras de teatro como "Los cinco de la pimiento" de Tomás Ireland en el número de mayo de 1964, la que estuvo dirigida por Víctor Otero, y los colaboradores Dantón Bravo, Alejandro Yáñez y otros. ${ }^{27}$

${ }^{22}$ En el primer número el equipo fue integrado por Oyarzún como Director, Hugo Quintana en redacción y administración, y los redactores Ernesto Águila, Carlos Encalada, Sergio Saavedra y Orlando Requena,

${ }^{23}$ De Ursic se sabe que provenía de la Escuela Técnica de Punta Arenas, Presidió la FEUT entre 1959 y 1961, viajo a Estados Unidos antes de las movilizaciones de mayo de 1961, y a su regreso decide quedarse en Cuba, donde trabaja en el equipos técnicos Comandante Pedro Sotto Alba hasta 1963..

${ }^{24}$ Artífice de la declaración del 25 de mayo y sobrino del escritor Pedro Gandulfo. De joven Juan Humberto desarrolló aptitudes de dirigente, siendo elegido, primero, Presidente del Centro de Alumnos de la Especialidad de Química y Presidente del Centro de Alumnos de la ETI, Presidente en los mismos cargos de la EII y Presidente de la FEUT. Posteriormente se desempeñó en numerosos cargos académicos, Director del Departamento de Química (unificado EII-ETI), destacando haber sido el último Director de la EII antes de crearse la Facultad de Ingeniería en 1972, cuando fue elegido Decano.

${ }^{25}$ Primo de Juan Humberto Vera Gandulfo.

${ }^{26}$ Ramón Dam en publicidad, Jaime Lagos en fotografía, los profesores como Armando Quezada y Enrique Álvarez V., y los estudiantes Eduardo Pavés, Guillermo Robé,

${ }^{27}$ También Roberto Jara, Jorge Araneda, Nancy Días, José Mena, Osvaldo Miranda, Milton Norambuena, Alejandro Szita, Arturo Perry en propaganda, José Ramón Olivares en dibujos, y los títulos de Alexis Álvarez. 


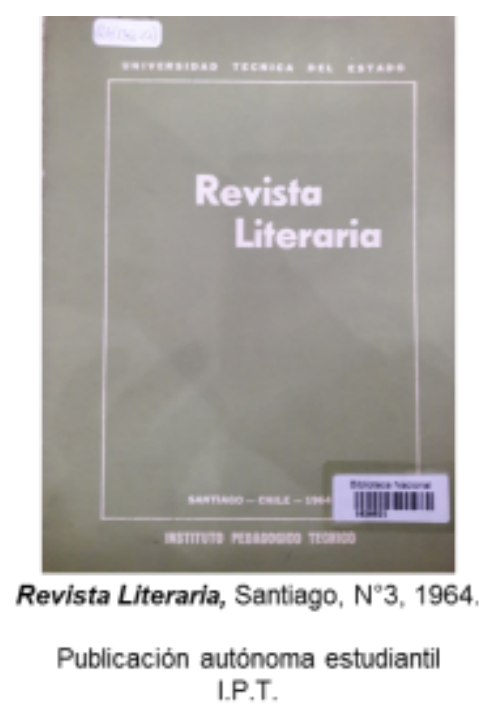
I.P.T.

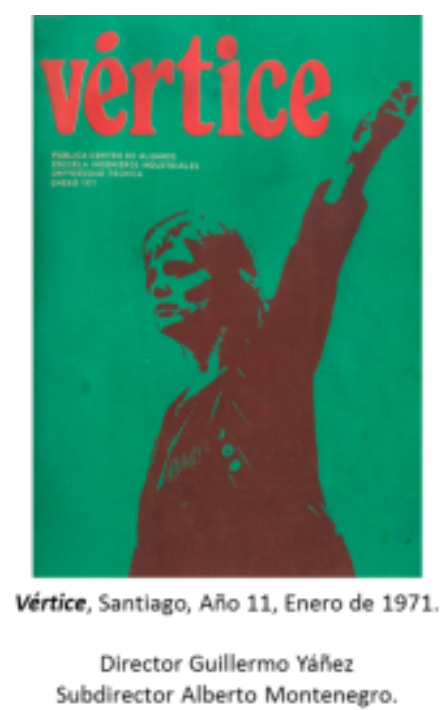

Subdirector Alberto Montenegro.

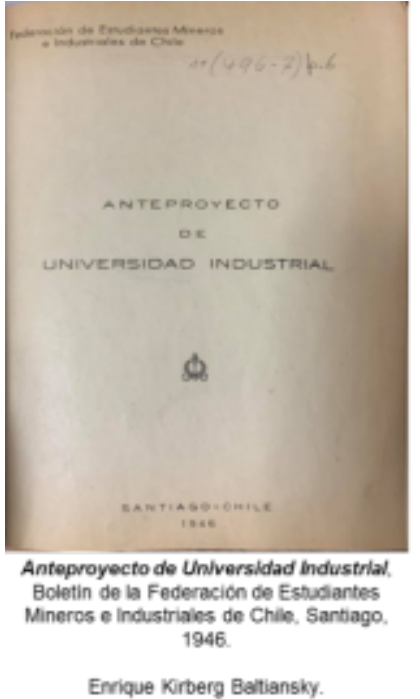

Enrique Kirberg Batiansky.

También destaca una publicación del Instituto Pedagógico Técnico, la Revista Literaria publicada desde 1962 y definida como una "Publicación Estudiantil Autónoma". Aunque sólo existe un número de 1964 y no se menciona los nombres de los integrantes del directorio, en ella se identifican a varios colaboradores. ${ }^{28}$ Entre ellos se encuentra al director del IPT desde fines de los cincuenta y profesor de literatura chilena Mario Osses Sáenz, y el poeta, ensayista, crítico venezolano y profesor de castellano del IPT Félix Armando Núñez. La revista fue impresa en veinte páginas tamaño carta, difundiendo textos críticos de libros, cuentos, poemas y otras actividades realizadas por el Taller Literario, dedicada casi en su mayoría a difundir los escritos del Concurso Literario de la UTE desde ese año.

Otra revista de larga duración fue Brecha, editada en ocho planas con formato periódico, la que abordó las acciones de la FEUT y el desarrollo cultural y deportivo. El primer número de junio de 1962 fue integrado por Otero como director, Juan Mosso en fotografía, y los colaboradores Ireland y Omar Martínez. ${ }^{29}$ Estas revistas muestran la especialización que tuvieron desde mediados de los años sesenta, ya que pasaron de tener un director junto a sus colaboradores, a contar con un Consejo de Redacción o de Dirección. En esa línea Brecha y Vértice cumplieron un rol articulador, ya que confluyeron estudiantes de diferentes regiones y generaciones que dieron continuidad a proyectos revisteriles encabezados por militantes comunistas y del Frente de Acción Popular (FRAP). Así durante sus primeros años, Brecha fue el órgano de difusión de la FEUT cuando fue dirigida por las Juventudes Comunistas (JJCC).

Entre 1962-1965 ese rol lo cumplió El Universitario como órgano oficial de la FEUT mientras fue encabezada por Guido Castilla en 1963 y 1964 y Vladimir Álvarez en 1965, militantes de la Juventud Demócrata Cristiana (JDC). La revista "nació a la vida estudiantil entre los fulgores de la lucha por la Reforma Universitaria” (El Decito, 1965, N², p. 2), y tuvo un equipo compuesto por su presidente Raúl Escalona, subdirector Paul Cortés, y fotos de Oscar González, abordando cuestiones sobre política estudiantil, consejo universitario, la FEUT y

${ }^{28}$ En dicho número participaron Federico Montecinos, Gloria Coloma, Dagoberto Aquevedo, Rosa Martínez, Ramón Pizarro, Adolfo Abarca, entre otros.

${ }^{29}$ También estuvieron colaborando Ariel Larenas, Reinal Mena, Sebastián Arancibia, Osvaldo Miranda, Eugenio Troncoso, Luis Garrido, y desde agosto Felipe Avelleira_y Enrique Gómez. 
variadas noticas. Durante 1965 se publicó otra revista para rendir cuentas y difundir a sus candidatos a la Federación llamada El Decito que fue dirigida por el químico Jaime Maureira Troncoso, ${ }^{30}$ la primera (y posiblemente la última) del Departamento de Publicaciones y Difusión de la JDC.

En el ámbito cultural la JDC impulsó grupos como el Club de Arte Folklórico creado y dirigido por Héctor Soto Veloso en octubre de 1964, siendo reemplazado más tarde por Maureira, quienes participaron con más de 150 estudiantes, en su mayoría mujeres. También se muestra que en la elección de 1965 la lista propuesta por la JDC a la FEUT estuvo integrada por dirigentes que participaron en la FEUT junto a Guido Castilla y Vladimir Álvarez o que se vincularon con otras federaciones universitarias. ${ }^{31}$ De hecho el candidato a presidente Mario Espinoza Vergara fue secretario de finanzas en 1962 y secretario de estudios en 1963, además de participar como delegado al Consejo Universitario del IPT en 1963-1964 y en el encuentro de Reforma Universitaria de la Unión de Federaciones Universitarias de Chile (UFUCH).

Cuando las JJCC vuelven a la FEUT en 1966, Brecha aumenta sus ediciones de dos a cuatro al año, donde encontramos una composición distinta con un consejo de redacción integrado por Susana Sánchez, Juan Proaño, Aquiles Torres, Mario Calvo, Ramiro Sepúlveda y Luis Verdugo, Mario "Nakor" Navarro ${ }^{32}$ y Roberto "Roco" Cortés Rojas en dibujo y diagramación. ${ }^{33}$ Mientras que en el último número encontrado en 1972 su director fue Miguel Concha y su representante legal fue el presidente de la FEUT Alberto Ríos Ponce, sin mencionar a sus colaboradores, redactores o diseñadores como una forma de reconocer el trabajo colectivo. Como vemos, son varias las figuras que se mezclan en sus primeros años, tales como Ireland, Yáñez, Otero o Martínez, en su mayoría estudiantes de la EII, mientras que a partir de 1966 hay un recambio de integrantes. Allí estaban Mario Navarro, Aquiles Torres y Nelson Meneses que participaban del periódico humorístico El Carlín, ${ }^{34}$ creado en 1964 como una parodia del diario El Clarín (Navarro en Rivera et al, 2016, p. 157), evidenciando que esta revista cumplió un rol articulador de sujetos y dirigentes de distintas escuelas que se formaron en las revistas.

${ }^{30}$ Presidente primer año de Química, Secretario Círculo de Química y Director del Conjunto Folklórico en 1965.

${ }^{31}$ El candidato a Vicepresidente Luis Inda Carreño había ocupado los cargos en la FEUT de Secretario General en 1962, Vicepresidente en 1963, Presidente del Centro de Alumnos de la ETI en 1964 y Delegado al Consejo Universitario del Grado Técnico en 1965. En los cargos de Delegado al Consejo estuvieron el estudiante de la ETI Osvaldo Huerta Pino, quien fue Secretario General de la UFUCH en 1963 y Relacionador Público de la FEUT en 1965, junto al estudiante de Historia en el IPT Jaime Arcos Marambio, quien también había participado del Congreso de la UFUCH en 1964. Además Arcos fue Gerente de la Cooperativa FEUT en 1963, que había sido fundada por Mario Espinoza y Vladimir Álvarez un año antes.

${ }^{32}$ Caricaturista y diseñador gráfico de la UTE en 1967. Participa de la revista Brecha bajo el pseudónimo de "Nakor", colaborando también con Topaze, Ultima Hora, Ramona. En 1970 asume con subdirector del Taller Gráfico UTE, además de ser invitado por el PC a ser parte de la campaña de Allende como autor de los afiche "¿Volverá? Nica...! (1970), como respuesta al afiche "Alessandri Volverá".

${ }^{33}$ Durante 1967 la integran Aquiles Torres como Director y un Consejo Redactor con Roberto "Roco" Cortés Rojas, Luis Verdugo y los dibujos de "Roco", mientras que al año siguiente su Director fue Cortez, y el Consejo Redactor con Nelson Meneses, Rodolfo Verdejo, Baris Sánchez, Aquiles Torres, las colaboraciones de Patricia Jorquera, Manolo Contreras y Víctor Sanvoval, y los dibujos de "Roco", incorporándose a finales de año Bernardo Jorquera, Manolo Segura, Washington Apablaza Manuel Contreras, lo que expresa un mayor interés de los estudiantes por participar en estos espacios. Al año siguiente su Director fue Iván Millas con los redactores Roberto Cortéz, N. Meneses Avilés, René Vergara, la colaboración de Mario Calvo, el Teknos, Coro y la Imprenta UTE, la diagramación de Sergio Albornoz y la asesoría técnica de "Roco".

${ }^{34}$ No fue posible encontrar ningún número, sólo citas en Ireland et al, 2016. 

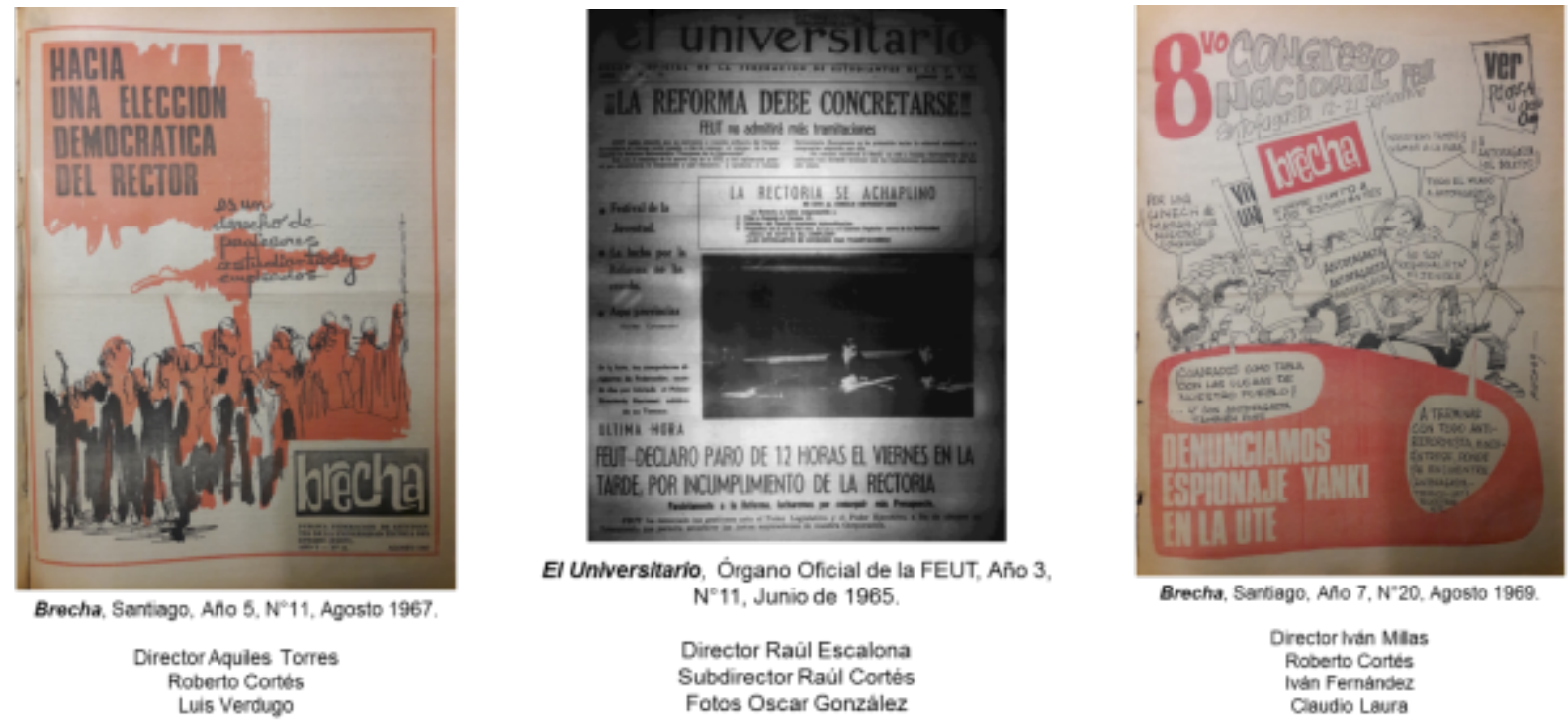

Las revistas como Brecha y Vértice junto a El Universitario y El Carlín muestran la continuidad de sujetos en redes de sociabilidad vinculadas a sus respectivos partidos políticos y el recambio de actores. Asimismo, cumplieron un rol en la generación de códigos comunes de entendimiento aportando en la construcción de una identidad y debates comunes, destacando la dinamización de espacios culturales en torno a las problemáticas estudiantiles. También integraron espacios como el Teatro Teknos creado por estudiantes de la Escuela de Ingenieros, donde hubo sujetos como Ireland que llegó a ser dramaturgo y editor durante los sesenta. Quienes protagonizaron espacios como el Movimiento Universidad Para Todos (MUPT) ${ }^{35}$ o las organizaciones inter universitarias y políticas desarrollando experiencias relevantes y de dialogo con las autoridades universitarias y del Gobierno de Eduardo Frei, buscando persuadir sobre la necesidad de reformar la UTE.

El movimiento estudiantil es relevante para desarrollar una identidad latinoamericana que llevó fuera del país a sujetos que desarrollaron redes y experiencias en lugares como Cuba. Allí destacan: Daslav Ursic que luego de viajar a Estados Unidos se queda en Cuba a inicios de 1961; Ciro Oyarzún que llegó en abril trabajando junto al Che Guevara, y Leonardo Fonseca que viajó en 1962, quienes regresan a Chile luego del triunfo de la Unidad Popular reflejando su interés por el proceso revolucionario chileno. Kirberg también fue a Cuba en 1962 con miembros del Instituto Popular ${ }^{36}$ y en 1970, donde invita a Fidel Castro a la UTE en noviembre de 1971. El Presidente de la FEUT de ese año también visita Cuba junto a Salvador Allende en noviembre de 1972, cerrando una gira mundial donde expusieron en diferentes países la experiencia de la UP, contribuyendo a la circulación de la experiencia revolucionaria chilena y cubana.

${ }^{35}$ Instrumento de lucha por la democratización del acceso creado a fines de 1964, participando estudiantes de la EII, IPT y EAO, en especial los miembros del FRAP universitario con militantes de la Juventud Comunista y la Juventud Socialista, quienes plantearon la realización de cursos para los egresados de las escuelas industriales, normales, técnicas femeninas y liceos para que prepararan la prueba de Bachillerato Industrial. Entre 1965 y 1967 consiguieron el ingreso directo de más de 2500 estudiantes a la UTE.

${ }^{36}$ Organismo de investigación auxiliar de los partidos políticos e independientes del FRAP creado alrededor de 1958, donde confluyeron intelectuales comunistas, socialistas, radicales y otros, entre ellos Clodomiro Almeyda, Graciela Álvarez, Aníbal Pinto Santa Cruz, Waldo Inostroza, Federico Kein, Max Nolff, entre otros. 
Revistas durante la reforma universitaria: 1968-1973

La última etapa asociada a las revistas inicia con la formación de la Comisión Nacional de Reforma Universitaria compuesta por académicos elegidos por los consejos de profesores de las escuelas de la UTE y la representación de la FEUT, donde existieron revistas institucionales y estudiantiles. Entre las primeras está el Boletín Académico publicado durante la dirección de Armando Quezada en la EII a inicios de 1969. Otras se relacionan con la Editorial UTE, como los Cuadernos de la Reforma del Área de Comunicaciones y Extensión desde 1969 hasta 1971; la Revista de la Universidad Técnica del Estado o Revista de la UTE de la Secretaría Nacional de Extensión y Comunicación publicada entre octubre de 1969 y junio de 1973; Contribuciones Científicas y Tecnológicas del Comité de Investigaciones desde 1971 (la única que tuvo continuidad tras el golpe de 1973); el periódico Unitécnica publicado entre mayo de 1970 y 1973; Presencia UTE publicado 1972 y 1973; y la revista Talleres de la Cultura publicada por la Secretaria Nacional de Extensión y Comunicaciones entre 1972 y 1973.

En cuanto a las revistas estudiantiles, tuvieron continuidad Brecha y Vértice, apareciendo a partir de 1971 revistas como Orbita de la Escuela de Ingeniería Eléctrica; UTE Furito del Frente Universitario Radical; y Alerta de la sección La Serena de la FEUT. El auge de las revistas se expresó en regiones, con suplementos como El Universitario Chilote de la Sub-sede Castro editada en 1972, y la revista de divulgación cultural pedagógica Estructura dirigida por Salvador Fuentes Vega y auspiciada por el Plan Cooperativo de la UTE en 1973. En ese sentido, se evidencia la diversificación de las producciones revisteriles durante la reforma en la UTE, demostrando que la práctica de la publicación editorial o revisteril se extendió a la mayoría de las sedes universitarias e institutos de la época.

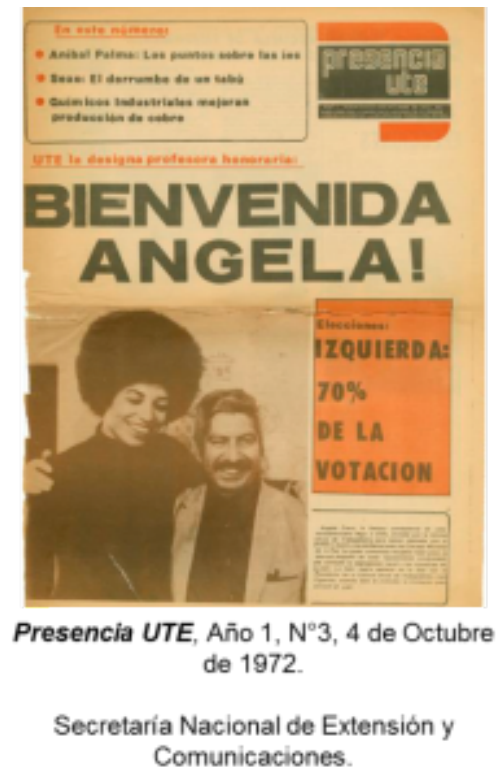
Comunicaciones.
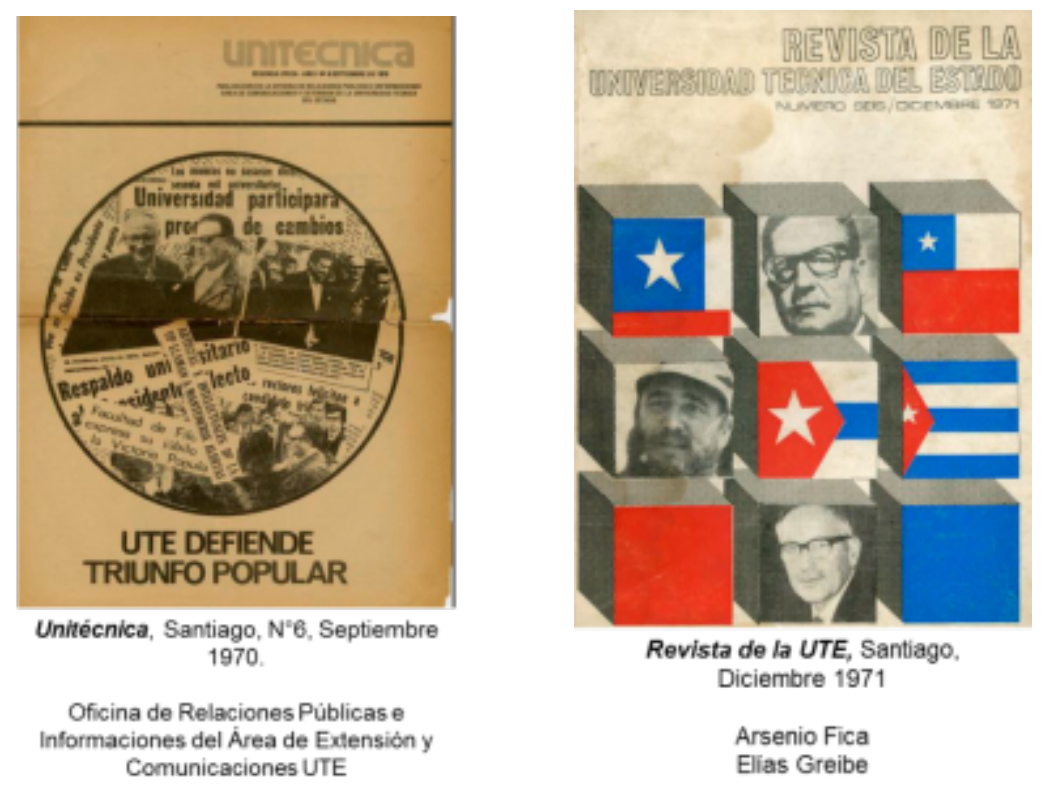
Las publicaciones institucionales se abocaron a la investigación y los debates en torno a la contingencia de la reforma y las transformaciones de la Unidad Popular, siendo publicada en octubre la Revista de la UTE con más de cien páginas, la que tuvo cuatro directores. Hasta mediados de 1971 publica tres números mientras fue dirigida por el comunista Fernando Lamberg, ${ }^{37}$ director general de la Sociedad de Escritores y premio Casa de las Américas en 1973. Luego es dirigida por Yerko Moretic, ${ }^{38}$ profesor que organiza el Área de Extensión y Comunicaciones en 1969, y fallece durante 1971 a los 44 años, publicando el $\mathrm{N}^{\circ} 4$ en septiembre y siendo reemplazado por el periodista Víctor Abudaye ${ }^{39}$ hasta diciembre. En la cuarta etapa se publica el $\mathrm{N}^{\circ} 6,7$ y 8 hasta mediados de 1972 al ser dirigida por Arsenio Fica, ${ }^{40}$ profesor y Director de la EII en reemplazo de Ireland en 1969, y finalmente es dirigida por Abudaye desde julio de 1972.

Su primera editorial afirmó que fue creada para "dar a conocer la realidad de la UTE [...] y facilitar la relación entre las diversas sedes, es decir, integrar la casa de estudios a los diversos aspectos de la realidad nacional" ( $\mathrm{N}^{\circ} 1$, octubre 1969, p. 1), incorporando desde el tercer número temáticas político-ideológicas y económico-productivas, y una página al final con información breve sobre el oficio, profesión, publicaciones y otras actividades de los escritores. Los colaboradores de la revista en sus primeras publicaciones fueron académicos o funcionarios de la UTE, ${ }^{41}$ y más tarde aparecen intelectuales y políticos ligados a la UP, como el ministro de agricultura y militante MAPU Jaques Chonchol, el diputado de la Izquierda Cristiana Luis Maira, el senador comunista Volodia Teitelboim, y discursos de Salvador Allende. Asimismo, colaboraron diseñadores gráficos que fueron estudiantes o académicos de publicidad, quienes trabajaron para el Taller Gráfico. ${ }^{42}$

${ }^{37}$ Profesor y escritor de amplia trayectoria, fue profesor de castellano en el Instituto Nacional y de Literatura Hispanoamericana en la UTE, directivo de diversas agrupaciones como la Sociedad de Escritores de Chile entre 1964-70, además de candidato a Rector en la UTE, militante PC, colaborador de la Revista Araucaria y locutor del programa radial Los Libros Hablan. Fue Director de la Revista UTE entre octubre 1969 y diciembre 1970. Obtuvo el Premio Casa de las Américas en 1973 y no pudo ser jurado en 1974. Fue exiliado en 1976 a Venezuela continuando se actividad académica, falleciendo en Caracas en 2011.

${ }^{38}$ Nacido en 1927, fue un profesor, escritor y crítico literario chileno de origen croata. En 1960 obtuvo el Premio Gabriela Mistral con "El relato de la pampa salitrera" y era parte del suplemento de El Siglo. Su militancia comunista lo llevo por varios años a China, haciendo clases de castellano en Pekín y traduciendo las obras completas de Mao Tse Tung. Además de otras publicaciones, en 1970 publica "José Carlos Mariátegui: su vida e ideario, su concepción del realismo" editado por la UTE. Fallece el 11 de julio de 1971 producto de una afección cardiaca, el mismo día de la nacionalización del cobre.

${ }^{39}$ Periodista, abogado y escritor. Tuvo una labor destacada en la Vicaría de la Solidaridad durante la dictadura.

${ }^{40}$ Ingeniero Químico. Fue elegido Director de la EII luego de que Ireland fuera elegido Secretario General. También participó en la Comisión para crear el Reglamento Carrera Académica en 1971, y en la Revista UTE, escribiendo artículos y como Director durante 1972. Alrededor de 1972 Fica fue nombrado Gerente General de ENAP.

${ }^{41}$ Entre ellos se cuentan al secretario general electo en 1972 Tomás Ireland, el profesor y director del departamento de ciencias sociales de la Facultad de Ingeniería Luis Razeto, el jefe de educación y ciencias sociales Sergio González, el coordinador docente del Área Académica Claudio Durán, los docentes del IPT Arcadio Escobar y Martín Pino, entre otros.

${ }^{42}$ Participaron diseñadores gráficos como Pablo Carvajal Gnecco, Elias R. Greibe (segundo al mando del Taller Grafico), Ricardo Ubilla Vera, Enrique Muñoz Abarca, Omar Rojas Olea (académico de la UTE), y Alejandro Lillo del Campo, sumándose el equipo de diagramación del Taller Gráfico. Cabe destacar que son Rojas y Griebe quienes donan números de la Revista de la UTE a la USACH, junto a Muñoz que rescata el material del Taller Gráfico en los días posteriores al golpe, entre ellos afiches que él diseñó de la exposición inconclusa "Por la Vida Siempre" que sería inaugurada el 11 de septiembre en todas las sedes de la UTE y diversas instituciones y organizaciones con las que colaboraba (Ireland et al, 2013, p. 233). 
Cuando comienza la reforma, donde para las fuerzas de izquierda Kirberg fue el mejor candidato a rector por su trayectoria, varios ex dirigentes estudiantiles ingresan con cargos directivos en la UTE. Allí destacaron Ciro Oyarzún como secretario ejecutivo del Comité Sectorial Pesquero de CORFO en 1971; Tomás Ireland como director del Departamento de Metalurgia en 1969, secretario general de la UTE en 1970 y miembro del grupo de Fiscalizadores de El Teniente desde 1971; Oscar Ripoll como funcionario del Servicio de Cooperación Técnica durante la UP; Leonardo Fonseca en la Empresa de Comercio Agrícola; Juan Vera que fue el primer decano de la Facultad de Ingeniería de la UTE en 1972; Mario Navarro que llego a dirigir el Taller Gráfico, fue director de la Secretaría Nacional de Extensión y Comunicaciones en 1971 y director del Departamento de Comunicaciones en 1973, entre otros. Allí espacios como los de Cine TV-UTE o la Dirección Nacional de Radios también contribuyeron a renovar las formas de circulación de los proyectos desarrollados, donde confluyeron grupos artísticos universitarios como el Conjunto Cuncumén, Inti-Illimani, Teatro Teknos, el Circo Minero y artistas como Charo Cofre, Víctor Jara, Ángel e Isabel Parra; quienes realizaron incontables giras por barrios populares, centros de trabajo, pueblos rurales y colegios como actividades de extensión universitaria.

También se publicaron periódicos como Unitécnica y Presencia UTE siendo impresa en formato tabloide con ocho páginas en dos colores. El primero fue la revista de la Oficina de Relaciones Públicas e Informaciones del Área de Extensión y Comunicaciones, entregando información sobre elecciones unipersonales, actividades deportivas y culturales, y sucesos relevantes de la universidad. Aunque no se pudo identificar a su comité editor, a esta publicación de ocho páginas se le pierde su rastro en julio de 1972, luego de las elecciones del rector Kirberg, el secretario general Ricardo Núñez y el Consejo Universitario. De hecho, pareciera ser que desde el 14 de septiembre esta fue reemplazada por el periódico Presencia UTE y la Secretaría Nacional de Extensión y Comunicaciones, incorporando noticias nacionales, debates sobre la televisión universitaria y distintos aspectos sobre las escuelas universitarias. Esta fue dirigida por los profesores y publicistas Carlos Munizaga Rivera, secundado Wiliam Venegas Galaz, junto a los redactores Gastón Saravia, Federico Quilodran y Adriana Gómez, la fotografía de Patricio Gómez, el diseño de Jorge Guastavino y los dibujos de Mario Navarro.

La revista Talleres de la Cultura dirigida por el actor, director, dramaturgo, docente y militante comunista Rubén Sotoconil Aranda, ${ }^{43}$ quien hizo su trayectoria en el teatro y cine chileno con directores como Aldo Francia y Miguel Littin (Rojas, 2019, pp. 144-146). Esta

\footnotetext{
${ }^{43}$ Nace en Trupán región del Biobío en 1917. Estudió en Los Ángeles donde fue conmovido por la Masacre de Ránquil en 1934, ocultando a uno de sus líderes (Zurita) en su casa, siendo delatado y preso en Concepción donde conoció a obreros de Lota en huelga de hambre a quienes se suma, experiencia que marca el inicio de su militancia comunista. Luego estudia (y abandona) Ingeniería en la Universidad de Chile y en 1940 se inscribe en el Instituto Pedagógico vinculándose al Teatro Experimental. Trabajo de profesor en colegios, reportero y secretario de redacción en El Siglo entre 1951-55 y dirigió la revista Nuestro Tiempo sobre política y marxismo internacional. En 1960 publica su traducción de "Manuscritos económicos y filosóficos" de Marx, filma "Deja que los perros ladren" de la obra de Sergio Vodanovic dirigida por Naum Kramarenco en 1961, año donde viajo como emisario del PC junto a Conjunto Cuncumén en una gira por la URSS. Entre 1963-64 viajó con su familia a China siendo traductor de Pekín Informa. A su regreso trabaja en "La Casa vieja" de Víctor Jara y en 1969 interpreta a un carabinero en "El Chacal de Nahueltoro de Miguel Littin. En la UP viaja a Valdivia donde funda y dirige la Escuela de Teatro de la Universidad Austral, participa en "Ya no basta con rezas" de Aldo Francia y otras obras de teatro, hasta que en 1972 fue contratado por la UTE hasta septiembre de 1973. Se queda en Chile durante la dictadura integrando iniciativas solidarias y culturales como SIDARTE, y durante la democracia continúa escribiendo y participando en obras hasta fallecer el 12 de marzo de 2002. Ver: Rojas, 2017.
} 
publicación de cincuenta páginas fue impresa en el Taller Gráfico de la UTE y tuvo la participación el diseño gráfico Pablo Carvajal Gnecco, quien también trabajaba en la Revista de la UTE. La revista dio énfasis a las tares culturales y el compromiso del escritor con un artículo de Carlos Maldonado, ${ }^{44}$ y también al Nuevo Teatro Popular nacido tras la firma del Convenio CUT-UTE en 1969. La revista que buscaba responder a dicho Convenio, contaba con un Suplemento donde se publicaron a los ganadores del Concurso de Teatro Social de la CUT, obtenido por Manuel Garrido con "La Maldición de la Palabra" en 1971, estrenada el 7 de octubre con la dirección de Sacha Manlay. La obra que ilustra el drama del campesinado en su búsqueda por la palabra o lenguaje, fue producto del Concurso de Dramaturgos organizado por la CUT, UTE, Universidad de Chile, y la Sociedad Nacional de Escritores, donde hubo influencia de nuevas líneas teatrales nacionales e internacionales.

En esta época las revistas político-culturales impulsadas principalmente por la Editorial UTE dirigida por Carlos Orellana, ${ }^{45}$ amigo y compañero del fotógrafo Antonio Quintana, el escritor Yerko Moretic y conductor radial Franklin Quevedo, quienes llegaron a trabajar durante la Reforma. Estas publicaciones respondieron a una estrategia comunicacional que buscó generar códigos comunes de entendimiento tanto al interior de la universidad como en el exterior, lo que se logró en la medida que la reforma fue implementándose. Allí estudiantes, profesores y funcionarios que escribieron adherían incluso al Partido Comunista o al menos a sectores cuya matriz ideológica de izquierda tuvieron afinidad por los trabajadores o el Convenio CUT-UTE, actores considerados centrales para el proceso de industrialización nacional.

\section{Conclusiones en torno al universo revisteril de la UTE}

En esta investigación hemos estudiado el universo revisteril en torno a la Universidad Técnica del Estado entre 1947 y 1973, destacando estudiantes, profesores y académicos que constituyeron espacios de sociabilidad para la creación, recepción y difusión de ideas y proyectos intelectuales, culturales, políticos y sociales. A partir del planteamiento inicial hemos comprobado algunos aspectos de nuestra hipótesis, la que plantea una relación entre actores que mediante las revistas político-culturales disputaron los marcos de significación en torno al sentido de la industrialización nacional y la educación técnica en la sociedad. Aunque la dificultad de acceder a fuentes impide profundizar en algunos sujetos, dinámicas, debates o espacios, pudimos identificar una composición diversa y transgeneracional de actores que en su agencia facilitaron la reposición de debates y propuestas formuladas en coyunturas anteriores.

Nuestra interpretación respecto al origen y evolución de la educación técnica, es que en la región chilena existió la necesidad de sostener un nivel de conocimiento y tecnología para explotación agrícola, artesanal, minero, técnico o industrial, donde existió oposición para desarrollar la ingeniería. Así mientras en la Académica de San Luis fue la institucionalidad colonial la que frenó el desarrollo de la educación técnica, más tarde fueron autoridades y grupos privilegiados que frenaron el desarrollo de la ingeniería industrial y su homologación con la ingeniería civil hasta mediados del siglo XX. Estas conflictividades y experiencias permiten

${ }^{44}$ Crítico de arte. Secretario General del Instituto Chileno de Investigaciones Marxistas. Autor de "Vida y obra de Alberto Valenzuela Llanos" y otros ensayos inéditos.

${ }^{45}$ Profesor de Castellano, Escritor y Editor. Dirigiendo la Editorial UTE se crean revistas como Cuadernos de la Reforma, Contribuciones Científicas y Tecnológicas, y la Revista de la Universidad Técnica del Estado. 
afirmar que en este proceso de larga duración se expresan dos proyectos de transformación, que si bien obedecen a dos grupos transgeneracionales que intercambiaron proyectos, esto no evitó contradicciones con las propuestas de otros actores que plantean la transformación desde una perspectiva diferente.

Por un lado, la creación de la UTE en 1947 y la promulgación del Estatuto Orgánico en 1952 se vincularon con el proyecto histórico de egresados y estudiantes que durante el siglo XX buscaron reorganizar la enseñanza técnica, presionando mediante espacios como la OTECH o la FEUT. Allí la implementación del proyecto de universidad industrial respondió a la necesidad de dignificar el trabajo técnico y regular su ejercicio profesional con los colegios profesionales, quedando las problemáticas estudiantiles postergadas por años. De hecho ese proyecto tuvo una orientación liberal en desmedro del proyecto industrializador de la FEMICH, el que buscaba la liberación nacional de la dependencia extranjera y no mejores condiciones de inversión a los empresarios, siendo el sector estudiantil derrotado en términos políticos pero no en términos socio-culturales.

Por otro lado, la reforma universitaria que inicia en 1967 y la Ley Orgánica de 1971 fue una respuesta a las demandas estudiantiles desde la primera candidatura de Kirberg en 1959, quienes dialogaron con sujetos y agrupaciones técnicas, obreras, culturales y populares transgeneracionales. Ellos disputaron el campo cultural y político tanto en la comunidad universitaria como al interior de instituciones estatales del Gobierno de la Unidad Popular, donde la UTE jugó un rol importante. En ese marco, constituyeron espacios y redes de sociabilidad en torno a la matriz política y cultural de la izquierda, buscando desarrollar la industrialización para que los sectores populares y obreros mejoraran sus condiciones de vida y de acceso a esta institución. Esto nos lleva a plantear que en los sesenta se formó una generación de líderes estudiantiles que agencian en la reforma universitaria junto a autoridades, académicos y funcionarios, constituyendo en una red de sociabilidad político-intelectual que ve cortado su desarrollo por la dictadura militar de 1973.

Las revistas político-culturales que hemos estudiado reflejan esa persistencia y reformulación de proyectos intelectuales en el imaginario colectivo de los actores de las escuelas técnico-industriales que dan forma a la UTE. Los actores de este universo revisteril problematizan la Universidad y construyeron horizontes de expectativas y propuestas de transformación con las que disputan los marcos de significación de la educación técnica y la industrialización nacional. De forma individual o colectiva, en las publicaciones se desarrolló la comunicación estratégica para generar códigos comunes de comprensión de la realidad, tanto en la comunidad universitaria como en los sectores sociales donde la UTE tuvo influencia con sus programas de educación técnica, permitiendo disputar el campo político-cultural para legitimar su programa de transformación universitaria y social.

Aquí vemos revistas institucionales editadas por profesores donde hubo colaboración de los alumnos y revistas estudiantiles editadas por sus organizaciones. Entre las primeras revistas político-culturales encontramos el boletín de la FEMICH de 1946, cuyo objetivo fue presionar para la creación de la universidad industrial. Si bien su concepto de industrialización para la liberación nacional no fue acogido, se pudo convocar a estudiantes, egresados, profesores y algunas autoridades para crear la UTE, la que comienza a funcionar tras la promulgación del Estatuto Orgánico en 1952. En ese contexto se publica la Revista de la OTECH, donde participaron protagonistas de las huelgas estudiantiles de 1931 como Alejandro Torres, Gustavo Erazo, Alfredo Serey y Enrique Kirberg, quienes buscaron "afianzar las conquistas y defender los 
derechos de los profesionales de la producción que sistemáticamente son postergados" (1952, p. 1), donde la UTE ejemplificó la escasa visión nacional para promover la industrialización.

Las revistas político-culturales aparecidas a fines de los años cincuenta, también muestran que en el proceso de construcción identitaria y tradición histórica de la UTE se crearon propuestas que más tarde se reformulan. Así revistas como Festividades Aniversarias y ERG de Concepción reflejan el nutrido campo cultural que surge junto al debate sobre las posibilidades que abre la educación técnica en la población infanto-juvenil y trabajadora con carreras de menor duración, propuestas que coinciden con la crisis institucional que lleva a la primera candidatura de Kirberg a la rectoría durante 1959. Algo similar ocurrió con la revista Vértice y Brecha, las que junto a difundir las actividades culturales, deportivas y orgánicas, se preocuparon de instalar en el debate público sus aspiraciones políticas, siendo central en sus ideas la imagen del Grito de Córdoba y la Reforma Universitaria argentina de 1918.

Tras la huelga de mayo de 1961, los estudiantes y sus organizaciones crearon una serie de estrategias para avanzar en su anhelo reformista, desarrollando experiencias culturales y políticas que apuntaron a desbordar los espacios institucionales mediante la acción colectiva, en especial desde las áreas de la cultura, el deporte y la política. Allí crearon espacios con una identidad técnica y popular como el Movimiento Universidad Para Todos, y también participaron de espacios como la Comisión Bipartita o el Congreso de Reforma para instalar en el debate público universitario sus propuestas de transformaciones. Por eso cuando comienza oficialmente la reforma en septiembre de 1967, manifiestan sus necesidades históricas en torno a desarrollar la doble democratización, la unificación de la administración de las escuelas, la creación de institutos profesionales con una Facultad de Ingeniería, entre otros.

Las revistas manifiestan la confluencia de dirigentes estudiantiles provenientes de todo el país, quienes participaron en espacios como el Teknos o la FEUT, quienes asistieron a la consolidación de las agrupaciones culturales creadas anteriormente, llegando incluso a ocupar cargos durante la reforma universitaria y la UP. En ese contexto destaca Enrique Kirberg, quien fue elegido rector en varias oportunidades, cuya trayectoria es transversal a la historia del movimiento estudiantil y de egresados técnicos. En cierta medida su itinerario refleja un proceso de larga duración que buscó transformar los marcos de significación de la universidad como una institución cultural que democratizó el acceso al conocimiento y materializó el vínculo universidad-sociedad mediante la extensión universitaria. En este proceso se crearon diferentes revistas político-culturales estudiantiles e institucionales que toman fuerza con la Reforma, difundiendo los avances reformistas y sus aportes científico-tecnológicos.

El proyecto contenido en la reforma universitaria tomó un carácter clasista que puede dividirse según sus dimensiones políticas, culturales e intelectuales. A nivel político, estuvo orientado a masificar el acceso de los sectores populares a esta institución cultural, desarrollando diferentes formas para facilitar el acceso de obreros, campesinos y sus hijos. Esto se desarrolló mediante el Convenio CUT-UTE, los Institutos Profesionales, la Escuela de Nivelación de Estudios, el proyecto de clases por radio, televisión y correspondencia, demostrando que no había impedimentos tecnológicos o comunicacionales para llevar la universidad a todos los rincones del país (Kirberg, 1981). En esa línea, aunque todas las universidades aumentaron su matrícula mediante institutos técnicos con cursos y carreras cortas, la UTE lo hizo en una proporción mayor debido a que buscó avanzar en la reparación de una injusticia histórica como lo fue la elitización del acceso a la educación superior, produciendo una memoria histórica que hasta el día de hoy la asocia con los sectores populares. 
Asimismo, la dimensión cultural del proyecto educacional estuvo orientada a llevar la universidad a las fábricas, minas, sindicatos y poblaciones mediante las Escuela de Temporada o el Curso Nacional de Auxiliares de Educación Parvulario. Estos cursos y escuelas realizadas en invierno, verano o todo el año, tuvieron como objetivo elevar el nivel cultural de mujeres y hombres, dando la oportunidad a miles de personas de adquirir elementos técnicos para sus oficios, o para que las mismas personas pudieran aprender cosas básicas para la vida cotidiana ${ }^{46}$. En ese marco, la contratación de agrupaciones culturales como el Teknos, o conjuntos musicales como Inti Illimani, Cuncumén, Víctor Jara, y otros, fue desarrollar su actividad con un sentido popular entregando acceso a la cultura a vastos sectores sociales. En ese marco, lo transformador de estos proyectos fue la intención de cambiar las estructuras sociales en su globalidad, y lo popular lo constituyó el vínculo con el mundo popular (estudiantes, trabajadores, técnicos), conteniendo también sus necesidades y expectativas.

En cuanto a la dimensión intelectual, la reforma se orientó a que técnicos, ingenieros y todas las carreras o cursos de corta duración incorporaran las ciencias sociales para desarrollar el pensamiento social crítico en las y los estudiantes y sus actividades profesionales. Aquí un elemento a destacar es la legitimidad que tuvo la enseñanza del marxismo y del materialismo dialectico, lo que se explica por la influencia que tuvo en aquella época el desarrollo de una sociología estructuralista y la Revolución Cubana, sumado a la radicalización de los intelectuales a finales de los años sesenta permitió que las ciencias sociales fueran enseñadas en la UTE. Aquellos proyectos fueron los que dieron a conocer el quehacer universitario y los resultados de la efectividad de la reforma universitaria, donde la forma de vinculación ya no sólo era de tipo asistencial, sino que para brindar el acceso a la educación superior mediante estudios académicos o la extensión universitaria.

Si bien no es la intención de este trabajo restar visibilidad al rol de las mujeres en este proceso, aclaramos que ellas ocuparon lugares de menor visibilidad producto de las condiciones de la época. Allí destacamos las figuras de la educadora María Teresa Femenias en la dirección de Radio UTE creada en 1957; Guacolda Antoine como la primera profesora de matemáticas de la Escuela de Ingenieros Industriales; la actriz Gladis del Rio y Gabriela Medina en el Teatro Teknos de la UTE; la dramaturga Isidora Aguirre; o la escritora Bélgica Watts. Asimismo, el ingreso de mujeres aumentó de un 6\% en 1964 hasta un 32\% en 1973 de un total de 32 mil estudiantes, ingresando en 1968 la primera mujer a ingeniería eléctrica Aída Fabbri, o la actual historiadora de la Universidad de Santiago Carmen Norambuena. En esa línea, también hemos buscado visibilizar su acción social y política, lo que sin duda requiere profundizar en diversos aspectos de sus trayectorias individuales y agencias junto a otros sujetos y grupos en otras coyunturas históricas.

Como vemos, desde los albores de la creación de la Universidad Técnica del Estado de Chile en 1947 -siendo desmembrada en 1981-, las revistas político-culturales y sus redes político-intelectuales buscaron influir en el debate sobre el carácter de la pretendida industrialización y las consiguientes reformas en la educación técnica e industrial. En este escenario apreciamos una suerte de continuidad sobre las exigencias estudiantiles y del profesorado progresista, desarrollándose una red junto a funcionarios, artistas, partidos e

\footnotetext{
${ }^{46}$ Allí destacan pequeños cursos del área: científica como matemáticas, física o mecánica; cultural como literatura, oratoria, deporte o familia; artística como danza, coro, cerámica o grabado; técnica con textil, mecánica, o eléctrica; Administración de empresas con planificación, gestión o computación; laboral con psicología laboral, formación de sindicatos o finanzas; y hogar con costura, primeros auxilios.
} 
intelectuales que llegó a su mayor desarrollo en el gobierno de la UP. No obstante lo anterior, en nuestra temporalidad de estudio es posible identificar algunas ideas o proyectos que se contraponen.

Si bien existen propuestas como la planteada por Horacio Aravena respecto a crear programas de estudio más cortos para "aprovechar mejor el capital humano especializándolo en diferentes funciones" (Festividades Aniversarias, 1958) y la del Programa de Educación para Trabajadores del Convenio CUT-UTE, ambas plantearon la resolución de una problemática desde una matriz política diferente. La primera apuntó desde una mirada liberal a que la educación técnica formara profesionales en las áreas de la industria sin que el Estado direccionara la industrialización, mientras que la segunda tuvo una perspectiva de izquierda que puso el acento en la formación de trabajadores para desarrollar la industrialización nacional y socializar las riquezas producidas en ese proceso. Esto también abre la interrogante respecto a si las dinámicas y conflictividades políticas manifestadas entre el gobierno de la UP y la oposición (de centro y derecha), se expresaron y/o resolvieron de la misma forma al interior de la UTE.

Otra contradicción se evidencia entre los estudiantes de Concepción y Santiago en torno a la institucionalización de los conjuntos artístico-culturales. Allí los primeros plantearon críticas a la institucionalización del Coro de la ETIC a fines de los cincuenta, mientras que en los sesenta la FEUT buscó institucionalizar el teatro Teknos y el Ballet Folklórico tal como se había hecho con el Coro de la UTE. Una lectura que podemos dar a este fenómeno, es que se vincula con la necesidad de los primeros por construir instituciones populares fuertes a través de las cuales generar pequeños espacios de poder al interior de la universidad, para así seguir disputando las transformaciones y aprovechar la influencia sobre los grupos culturales, deportivos y de voluntariados. Mientras que para los estudiantes de los años sesenta la situación fue diferente, ya que se encontraban ad portas de la implementación de la reforma universitaria que respondía a las necesidades de los actores postergados históricamente.

Es importante relevar la función de las revistas político-culturales como una estrategia comunicacional con una dimensión doble, una guiada por los objetivos de difusión interna de los logros de la reforma y las investigaciones académicas, y otra por el acercamiento de la universidad a la sociedad. Aquí se tiende a pensar la comunicación como factor determinante para el funcionamiento interno y externo, produciendo lógicas comunicativas donde se despliegan mecanismos de trabajo que permitieron que esa comunicación interna fluya a partir de códigos y lenguajes comunes donde no existe asimetría de información y donde el mensaje se pueda asimilar y de esa forma amplificar. Como estrategia de extensión universitaria, en ella se rompe el campo cerrado de la universidad para abrirse al país, expresando la disolución de la tensión entre el campo cultural y el campo político propio del contexto de los sesenta-setenta, donde el arte y la investigación se ponen al servicio de la transformación de la sociedad.

En estos procesos se subentiende que para los actores que estudiamos, la acción colectiva fue una forma legítima de participación democrática de los sectores populares. Y en un vínculo con el tiempo presente, a través de estas acciones se ha vuelto a colocar en el centro de la discusión el problema del acceso a la educación y el rechazo a su mercantilización. El Mochilazo de 2001, las movilizaciones estudiantiles en 2006 y 2011, el Mayo feminista de 2015, y el contexto previo a la Revuelta de Octubre de 2019, son claros ejemplo de ello. Por consiguiente, reponer este universo revisteril y a sus actores, permite pensar en la actualidad de producir un proyecto educacional que recupere y actualice la experiencia de la UTE como un proyecto histórico para impulsar la industrialización nacional y la formación profesional de los sectores 
populares, pero incorporando las preocupaciones actuales en torno al daño medioambiental que producen procesos como la industrialización sin considerar sus efectos sobre los territorios.

Para finalizar, debemos señalar que nuestro trabajo abre una serie de temas de investigación paralelos que permiten enriquecerlo. Así se abren temas en torno al origen y desarrollo del movimiento estudiantil vinculado a la educación técnica a lo largo del siglo XX; la recuperación de la historia de las asociaciones y colegios profesionales de técnicos e ingenieros así como la pregunta respecto a su alejamiento de las conflictividades de la UTE; respecto al desarrollo de las expresiones artístico-culturales y su vínculo con movimientos nacionales e internacionales; y también sobre los debates en torno a la educación técnica y su relación con los proyectos de similares características en otros lugares de América Latina y el mundo. En vista del escenario que impide acceder fácilmente a las fuentes necesarias para responder lo anterior, estas posibles investigaciones quedaran suspendidas hasta que las condiciones lo permitan.

\section{Bibliografía}

Adler, Larisa (2002). Redes sociales y partidos políticos en Chile. Revista Redes (№3).

Aránguiz, Waldo (2000). Presencia coral de Chile en América Latina. Santiago: Revista Musical Chilena, (Vol. 54, N¹94).

Brunner, José y Gonzalo Catalán (1985). Cinco estudios sobre la cultura y sociedad. Santiago: FLACSO.

Bustelo, Natalia (2018). Todo lo que necesitas saber sobre la reforma universitaria. Buenos Aires: Editorial Paidós.

Casali, Aldo (2015). Reforma universitaria en Chile, 1967-1973. Pre-balance histórico de una experiencia frustrada. Santiago: Intus-Legere Historia, Vol. 5, Nº1, pp. 81-101.

Castillo, Eduardo (2015) Artesanos, Técnicos e ingenieros. La Escuela de Artes y Oficios de Santiago, EAO. Concepción: Atenea, N511, julio, pp. 247-256.

Cifuentes, Luis (1993). Kirberg: testigo y actor del siglo XX. Santiago: Fundación E. Kirberg. (1994) (ed.). La Reforma Universitaria en Chile 1967-1973. Santiago: Fundación E. Kirberg.

Devés, Eduardo (2007). Redes intelectuales en América Latina. Hacia la constitución de una comunidad intelectual. Santiago: IDEA-USACH.

Garretón, Manuel \& Martínez, Javier (1985). Universidades chilenas: historia, reforma e intervención. Tomo I al V. Santiago: Sur.

Di Pasquale, Mariano (2011). De la historia de las ideas a la nueva historia intelectual: Retrospectivas y perspectivas. Un mapeo de la cuestión. U. de Talca: Revista UNIVERSUM, (N²6, Vol. 1), pp. 79 a 92.

Gallardo, Juanita (2015). Vivir enfrentando las flechas: relatos de vida de la EAO-UTE-USACH. Santiago: Corporación Cultural USACH.

Garretón, Manuel (2005). Las ciencias sociales en Chile. Institucionalización, ruptura y renacimiento. Versión en castellano de "Social Sciences and society in Chile: institutionalization, breakdown and rebirth in Chile", México, Social Sciences in Latin America, (volumen 44, $\mathrm{N}^{\circ} 2-3$ ), Junio Septiembre. Disponible en: 
[http://www.manuelantoniogarreton.cl/documentos/07_08_06/sociales.pdf]. Revisado el 18 de julio de 2020.

Gilman, Claudia (2003). Entre la pluma y el fusil: debates y dilemas del escritor revolucionario en América Latina. Buenos Aires: Siglo XXI.

Ireland, Tomas \& Rivera, Francisco (2016). LA UTE VIVE: Memorias y testimonios de la reforma universitaria en la Universidad Técnica del Estado. Chile 1961/1973. Santiago: Corporación Cultural USACH.

Isava, Luis (2009). Breve introducción a los artefactos culturales. México: Revista Estudios, UNAM, (Vol. 17), pp. 439-452.

Kirberg, Enrique (1981). Los nuevos profesionales. Educación Universitaria para trabajadores 1968-1973. México: Universidad de Guadalajara.

Lozoya, Ivette (2014). Pensar la revolución: intelectuales y pensamiento latinoamericanos en el MIR chileno 1965-1973. Santiago: Tesis para el grado de Doctora en Estudios Americanos, Mención en Historia.

Markarian, Vania (2012). Uruguay, 1968. Algunas líneas de análisis derivadas del estudio de la protesta estudiantil en un país periférico. Uruguay: Espacio, Tiempo y Educación, $\left(\mathrm{n}^{\circ} 6\right.$, vol.1), pp. 129-143.

Moyano, Cristina e Ivette Lozoya (2019). "Intelectuales de izquierda en Chile”: ¿de la politización a la tecnocracia? Debates sobre la función política y el ser del intelectual entre 1960 y 1990. México DF: Signos Históricos (Vol. XXI, N41), pp. 192-229.

Moyano, Cristina (2011). La historia política en el bicentenario: entre la historia del presente y la historia conceptual. Reflexiones sobre la nueva historia política. Revista de Historia Social y de las Mentalidades, (Volumen 15, N¹), pp. 227-245.

Ory, P. \& Sirinelli, J.F. (2007). Los intelectuales en Francia. Del caso Dreyfus a nuestros días (Traductor Evelio Miñano). Universitat de Valencia.

Pluet-Despatin, Jacqueline (1992). "Contribución a la Historia de los Intelectuales. Las revistas" (traducción de Horacio Tarcus; revisión técnica de Margarita Merbilhaá), en AMÉRICALEE. El portal de publicaciones latinoamericanas del siglo XX. Disponible en: $<$ www.americalee.cedinci.org $>$

Queipo de Llano, Genoveva (2004). "La historia de los intelectuales españoles en el siglo XX”, en Rémond, René et al (Eds.), Hacer la historia del siglo XX. España: Editorial Biblioteca Nueva, pp. 333-348.

Rebolledo, Loreto (1995). Género y Espacios de Sociabilidad. La Escuela como Lugar de Encuentro con los "Otros". II Congreso Chileno de Antropología. Colegio de Antropólogos de Chile A. G, Valdivia.

Rivera, Francisco (2018). Universidad y cambio social: la experiencia histórica de la Universidad Técnica del Estado Chile 1947-81. Tesis para optar al grado de Magister en Historia con Mención en América Latina, USACH.

Tarcus, Horacio (2020). Las revistas culturales latinoamericanas. Giro material, tramas intelectuales y redes revisteriles. Buenos Aires: CEDINCI y Tren en Movimiento.

Zamorano, Cesar (2018) (Ed.). Escrituras en tránsito. Revistas y redes culturales en América Latina. Santiago: Cuarto Propio. 